\title{
Percepção de nutricionistas sobre sua atuação profissional no contexto de supervalorização do corpo magro e escultural
}

\author{
The perception of nutritionists about their professional \\ performance in the context of overvaluing the lean and \\ sculptural body
}

\author{
Fernanda Fonseca Barbosa Mendes', Maria Vilela Pinto Nakasu² \\ ${ }^{7}$ Hospital de Clínicas de Itajubá \\ ${ }^{2}$ Faculdade de Medicina de Itajubá
}

Contato: Fernanda Fonseca Barbosa Mendes - fernandafonsecabmendes@gmail.com

\begin{abstract}
Resumo
Objetivo: Identificar a percepção de nutricionistas sobre sua atuação profissional no contexto de supervalorização do corpo magro e escultural. Método: Foi realizado estudo transversal, de abordagem qualitativa com nutricionistas de Itajubá-MG. Todos eram maiores de 18 anos e ativos na profissão. A determinação da amostra foi de 12 nutricionistas, número suficiente para se atingir a saturação (Field Methods). Para a coleta de dados foi utilizado questionário sociodemográfico e entrevistas semiestruturadas, que foram gravadas e transcritas para posterior análise de acordo com a Metodologia de Bardin. Os depoimentos foram submetidos à análise de conteúdo, modalidade temática transversal. Resultados: Foram identificadas cinco temáticas relacionadas com os objetivos do estudo: 1. Nutrição e estética; 2. Impacto das dietas restritivas; 3. Busca pelo corpo perfeito; 4. Dificuldades no trabalho como nutricionista; 5. Saúde como bem-estar físico, mental e social. Conclusão: Foi possível identificar uma percepção negativa dos impactos causados pelo ideal moderno de corpo magro e escultural na atuação profissional do nutricionista.
\end{abstract}

Palavras-chave: Nutricionistas. Saúde. Estética. Meios de Comunicação.

\begin{abstract}
Objective: To identify the perception of nutritionists about their professional performance in the context of overvaluing the lean and sculptural body. Method: A qualitative cross-sectional study was carried out by nutritionists from ItajubáMG. All were over 78 and active in the profession. The sample was determined from 12 nutricionists, enough to reach saturation (Field Methods). For data collection, a sociodemographic questionnaire and non-directed interviews were used, which were recorded and transcribed for later analysis according to the Bardin Content Analysis Methodology. Results: 92\% of the participants were female. Five central themes were related to nutritionists' perception of their professional performance in the context of overvaluing the lean and sculptural body: 1. Nutrition and aesthetics; 2. The impact of restrictive diets; 3. Search for the perfect body; 4. Difficulties at work as a nutritionist; 5 . Health as well as physical, mental and social
\end{abstract}


well-being. Conclusion: It was possible to identify a negative perception of the impacts caused by the modern ideal of a lean and sculptural body in the professional performance of the nutritionist.

Keywords: Nutricionists. Health. Esthetics. Communications Media.

\section{INTRODUÇÃO}

A nutrição é uma área relativamente jovem no Brasil. O primeiro curso foi criado em 1939, em São Paulo e a regulamentação da profissão ocorreu somente em 1967¹. Os cursos de saúde no Brasil, principalmente na área médica, possuem uma formação com base no modelo biologicista, com foco na prática curativa. Uma dimensão estritamente biológica é priorizada, situando em segundo plano as dimensões psicológica e social ${ }^{2}$. Foram médicos nutrólogos que tomaram a frente da criação do curso de nutrição no país, o que pode explicar seu caráter biologicista² .

O nutricionista é o profissional responsável pelos cuidados relativos à alimentação e nutrição das pessoas, utilizando o alimento e a comensalidade como instrumento de trabalho3 ${ }^{3}$ A consideração do ser humano em sua dimensão puramente biológica pode restringir o profissional nutricionista na obtenção de resultados efetivos, porventura acarretando em falhas de estratégias utilizadas em mudanças comportamentais, aconselhamento e educação nutricional ${ }^{4}$. Segundo o Código de Ética e Conduta do Nutricionista, este profissional deve atuar visando a promoção da saúde e prevenção de doenças, indo, portanto, além do sentido biológico da alimentação ${ }^{3}$.

A relação homem/alimento envolve valores e significados sociais, culturais, religiosos, biológicos e psicológicos, onde o comer pode se tornar um momento de partilha, de trocas afetivas e alivio de tensões emocionais ${ }^{1,5}$. A alimentação de uma sociedade é construída de acordo com o contexto sociocultural vigente e, por esta razão, está sujeita à influência maciça dos meios de comunicação de massa, importantes geradores de opiniões ${ }^{6}$.

No final do século XX, a concepção de corpo para a sociedade se transformou significativamente, acarretando em influências diretas sobre a alimentação ${ }^{6}$. Se, antes a lógica repressiva escondia o corpo, no momento posterior ele passou a ser evidenciado, desejado e, o corpo magro e malhado tornou-se a grande referência de imagem corporal perfeita ${ }^{6}$. O propósito de alcançar o corpo perfeito passou a ser 
associado fortemente à ideia de saúde, beleza e felicidade, e a alimentação passou a ser considerada o caminho através do qual se alcançaria o novo ideal de perfeição ${ }^{6,7}$. A formação da imagem corporal de cada um sofre influência direta dos meios de comunicação: a corrida pelo corpo perfeito intensifica-se quanto mais corpos inalcançáveis a mídia expõe, podendo gerar atitudes e comportamentos alimentares disfuncionais e prejudiciais à saúde ${ }^{7,8,9}$. Portando um novo significado, a nutrição deixa de ser vista como uma estratégia voltada à promoção da saúde e prevenção de doenças, tornando-se uma prática dedicada a esculpir corpos perfeitos ${ }^{6,7}$.

Profissionais da dieta, esculpidores de corpos, emagrecedores, são termos que vem sendo muito utilizados para definir o nutricionista. Dessa forma, torna-se relevante investigações que se propõem a refletir sobre as formas de atuação do nutricionista na atualidade. Neste contexto, este estudo objetiva identificar a percepção de nutricionistas sobre sua atuação profissional no contexto de supervalorização do corpo magro e escultural. O estudo foi feito com nutricionistas de uma cidade do sul de Minas Gerais, durante o ano de 2019.

\section{MÉTODO}

O presente estudo, transversal, de abordagem qualitativa, foi realizado pela produção de base empírica por meio do trabalho de campo junto a 12 profissionais nutricionistas residentes em Itajubá-MG. Os critérios de inclusão foram ter graduação completa de nutrição, ser nutricionista atuante, ter mais de 18 anos e residir em Itajubá-MG. A amostragem foi não-probabilística.

Considerando-se que, nas pesquisas qualitativas, não se calcula o tamanho da amostra, em um estudo da "Field Methods", Guest et al. ${ }^{10}$ propôs que 12 entrevistas eram suficientes para chegar à saturação ${ }^{10}$. A determinação da amostra foi, portanto, de 12 nutricionistas inicialmente, e se necessário, o tamanho da amostra seria aumentado até que se alcançasse a saturação. No tipo de amostragem por saturação, o pesquisador identifica que a partir de um determinado ponto (ponto de saturação) começa haver repetição de informações obtidas dos sujeitos da pesquisa e tal repetição não traz acréscimos significativos à pesquisa, começa a existir redundância nas respostas obtidas e, a partir desse ponto, o pesquisador encerra a amostragem $^{11}$. Para evitar dificuldades técnicas para uma constatação objetiva da saturação, foi seguida uma sequência de oito passos procedimentais de tratamento e análise de dados coletados nas entrevistas, tal como determina Fontanela e Saidel ${ }^{12}$. 
A pesquisa foi iniciada apenas após a aprovação pelo Comitê de Ética em Pesquisa (CEP) pelo número do parecer: 3.027.324. A abordagem dos participantes partiu de um convite informal dos pesquisadores, foram expostos os objetivos do trabalho e esclarecidas possíveis dúvidas. Com a adesão por parte dos sujeitos da pesquisa, foram marcados data e horário conveniente para ambas as partes. No dia e hora marcados, foram aplicados o Termo de Consentimento Livre e Esclarecido e um questionário sócio demográfico, com perguntas sobre informações pessoais, como nome, sexo, idade, naturalidade, estado civil, escolaridade e renda mensal. Em seguida, foram realizadas as entrevistas semiestruturadas, que constituem o principal instrumento de coleta de dados nas pesquisas qualitativas no campo da saúde. Para os profissionais de saúde, saber o que as pessoas sentem e imaginam permite uma relação mais adequada com o paciente ${ }^{13}$.

As entrevistas semiestruturadas se basearam na percepção dos nutricionistas sobre a supervalorização do corpo magro e escultural. Os seguintes temas foram abordados junto aos profissionais: o papel do nutricionista na atualidade; as dificuldades e desafios encontrados na prática profissional; opiniões sobre dietas restritivas, saúde e padrões de beleza vigentes na sociedade atual. As entrevistas foram gravadas com permissão dos participantes e, posteriormente, transcritas na integra para análise. Para efeito de apresentação dos resultados e para garantir o anonimato dos sujeitos da pesquisa, cada participante foi codificado com a letra $\mathrm{S}$, seguida do número de ordem da entrevista.

Os dados coletados foram analisados segundo a metodologia de análise de conteúdo de Bardin $^{14}$. A técnica da análise temática é adequada à investigação qualitativa do material sobre saúde ${ }^{11}$. As diferentes fases da análise de conteúdo organizaram-se em torno de três polos, conforme Bardin ${ }^{14}$ : 1) A pré-análise; 2) A exploração do material, por meio de contato exaustivo com esse, e 3) O tratamento dos resultados: a inferência e a interpretação. Tal procedimento permitiu descrever o conteúdo das mensagens, e levantar indicadores qualitativos que levaram à inferência de conhecimentos relativos à percepção de nutricionistas sobre sua atuação profissional no contexto de supervalorização do corpo magro e escultural.

Foram respeitados os procedimentos éticos para pesquisas com seres humanos, contidos na Resolução 466/12, do Conselho Nacional de Saúde. 


\section{RESULTADOS E DISCUSSÃO}

Participaram deste estudo 12 nutricionistas. Dos participantes, 92\% pertencem ao sexo feminino, com média de idade de 31,41 anos ( \pm DP 5,97); 33\% referem ser naturais do Estado de São Paulo, 58\% declaram-se solteiros, e 42\% afirmam ter cursado uma pós-graduação após sua formação acadêmica. Quanto à renda salarial, $50 \%$ referem renda entre 1.000 e 3.000 reais, $17 \%$ se formaram na Universidade do Vale do Sapucaí (UNIVAS) e 17\% se formaram na Fundação de Ensino e Pesquisa de Itajubá (FEPI). Os dados relatados podem ser melhor visualizados na tabela a seguir:

Tabela 1 - Características sociodemográficas de nutricionistas que atuam em Itajubá-MG (n=12)

\begin{tabular}{|c|c|c|}
\hline Variáveis & Freq. Ab. & Freq. $\mathbf{R}$. \\
\hline \multicolumn{3}{|l|}{ Sexo } \\
\hline $\begin{array}{l}\text { Feminino } \\
\text { Masculino }\end{array}$ & $\begin{array}{c}11 \\
1\end{array}$ & $\begin{array}{c}92 \% \\
8 \%\end{array}$ \\
\hline \multicolumn{3}{|l|}{ Naturalidade } \\
\hline $\begin{array}{l}\text { Congonhas } \\
\text { São Paulo } \\
\text { Itajubá } \\
\text { Não respondeu } \\
\text { Ribeirão Preto } \\
\text { Rio de Janeiro }\end{array}$ & $\begin{array}{l}1 \\
4 \\
2 \\
2 \\
1 \\
2\end{array}$ & $\begin{array}{c}8 \% \\
33 \% \\
17 \% \\
17 \% \\
8 \% \\
17 \%\end{array}$ \\
\hline \multicolumn{3}{|l|}{ Estado Civil } \\
\hline $\begin{array}{l}\text { Solteiro } \\
\text { Casado } \\
\text { Divorciado } \\
\text { Viúvo }\end{array}$ & $\begin{array}{l}7 \\
3 \\
2 \\
0\end{array}$ & $\begin{array}{c}58 \% \\
25 \% \\
17 \% \\
0 \%\end{array}$ \\
\hline \multicolumn{3}{|l|}{ Escolaridade } \\
\hline $\begin{array}{l}\text { Sem pós } \\
\text { Pós-graduação incompleta } \\
\text { Pós-graduação completa }\end{array}$ & $\begin{array}{l}4 \\
3 \\
5\end{array}$ & $\begin{array}{l}33 \% \\
25 \% \\
42 \%\end{array}$ \\
\hline \multicolumn{3}{|l|}{ Renda } \\
\hline $\begin{array}{l}\text { Até } 1000 \text { reais } \\
\text { De } 1000 \text { a } 3000 \\
\text { De } 3000 \text { a } 5000 \\
\text { Acima de } 5000\end{array}$ & $\begin{array}{l}1 \\
6 \\
4 \\
1\end{array}$ & $\begin{array}{c}8 \% \\
50 \% \\
33 \% \\
8 \%\end{array}$ \\
\hline \multicolumn{3}{|l|}{ Instituição de formação } \\
\hline $\begin{array}{l}\text { UFMG } \\
\text { UNIVAS } \\
\text { Centro Universitário São Camilo } \\
\text { Universidade Federal do Vale do } \\
\text { Jequitinhonha e Mucuri }\end{array}$ & $\begin{array}{l}1 \\
2 \\
1 \\
1\end{array}$ & $\begin{array}{l}8 \% \\
17 \% \\
8 \% \\
8 \%\end{array}$ \\
\hline FESB & 1 & $8 \%$ \\
\hline FEPI & 2 & $17 \%$ \\
\hline UNISEP & 1 & $8 \%$ \\
\hline UFLA & 1 & $8 \%$ \\
\hline Universidade Federal de Alfenas & 1 & $8 \%$ \\
\hline FMIT & 1 & $8 \%$ \\
\hline
\end{tabular}

Fonte: Do instrumento do estudo. 
No que se refere ao ano de conclusão da graduação, $17 \%$ relatam ter concluído no ano de 2003, 17\% concluiu em 2012 e 17\% em 2018. Quanto à atuação nutricional, 50\% dos entrevistados relatam atuar no campo de nutrição clínica. Os dados mencionados encontram-se na tabela a seguir:

Tabela 2 - Características sociodemográficas de nutricionistas que atuam em Itajubá-MG (n=12)

\begin{tabular}{lcc}
\hline Variáveis & Freq. Ab. & Freq. R. \\
\hline Ano de conclusão & 2 & $17 \%$ \\
2018 & 2 & $17 \%$ \\
2012 & 2 & $17 \%$ \\
2003 & 1 & $8 \%$ \\
2013 & 1 & $8 \%$ \\
2006 & 1 & $8 \%$ \\
2014 & 1 & $8 \%$ \\
2017 & 1 & $8 \%$ \\
2008 & 1 & $8 \%$ \\
2007 & & \\
Área de atuação nutricional & 4 & $33 \%$ \\
Hospitalar & 1 & $8 \%$ \\
Materno Infantil & 6 & $50 \%$ \\
Nutrição Clínica & 1 & $8 \%$ \\
Emagrecimento Gestação & & \\
\hline
\end{tabular}

Fonte: Do instrumento do estudo

De acordo com a metodologia de análise de conteúdo de Bardin, foi realizada a revisão do conteúdo das entrevistas e das unidades temáticas identificadas afim de assegurar que os achados representavam experiências dos informantes. Foram respeitados os procedimentos éticos para pesquisas com seres humanos, contidos na Resolução 466/12, do Conselho Nacional de Saúde.

As cinco temáticas centrais encontradas nas entrevistas e relacionadas à percepção dos nutricionistas sobre sua atuação profissional no contexto de supervalorização do corpo magro e escultural, foram as seguintes:

Quadro 1 - Temáticas centrais encontradas nas entrevistas não-diretivas

\begin{tabular}{|l|l|}
\hline Nutrição e estética & $79 \%$ \\
Impacto das dietas restritivas & $69 \%$ \\
Busca pelo corpo perfeito & $66 \%$ \\
Dificuldades no trabalho como nutricionista & $54 \%$ \\
Saúde como bem-estar físico, mental e social & $37 \%$ \\
\hline
\end{tabular}

No presente estudo, há prevalência do gênero feminino, corroborando com a literatura, que mostra predominância do gênero feminino em estudos com 
nutricionistas ${ }^{1,15,16,17}$. Os primeiros cursos de nutrição no Brasil foram oferecidos pelo Serviço de Alimentação da Previdência Social (SAPS) e destinados exclusivamente às mulheres, o que auxilia na compreensão do perfil predominantemente feminino ${ }^{18}$. $O$ curso de nutrição se modificou ao longo dos anos, incluindo outros campos de atuação, porém ainda há forte associação da nutrição com a atividade de cozinhar, o que culturalmente é associado à uma prática feminina ${ }^{1}$.

\section{Nutrição e estética}

É essencial que o nutricionista priorize a saúde da população ${ }^{19}$, desenvolvendo práticas que visem saúde, segurança alimentar e nutricional ${ }^{3}$. Porém, observa-se que, muitas vezes, o nutricionista é visto como um profissional da estética. Estudo no interior do Rio Grande do Sul constatou que grande parte das pessoas que procuram atendimento nutricional estão em busca de mudanças estéticas, colocando a saúde em segundo plano ${ }^{20}$. A pesquisa foi realizada com nutricionistas da localidade, que relataram que a maioria dos pacientes chega em busca da perda de peso com objetivos estéticos ${ }^{20}$.

O presente estudo identificou um número expressivo de referências que relacionam nutrição à saúde e não à estética. Assim, diz S1: "Acho que chega até ser uma ofensa pensar no nutricionista como um profissional emagrecedor, ou alguma coisa do tipo. Muito além disso, a gente não passa 5 anos estudando para emagrecer os outros... acho que o nutricionista... antes de tudo, é um profissional da saúde..."

O nutricionista deve pautar sua atuação na promoção da saúde e prevenção de doença, garantindo o direito de todos a uma alimentação adequada e segura ${ }^{3,15}$. No entanto, há estudos que se reportam à dicotomia entre teoria e prática na formação dos nutricionistas ${ }^{21,22}$; muitas vezes esses profissionais atuam de forma a atender os interesses econômicos e não às demandas sociais ${ }^{23}$.

Um exemplo de conflito entre teoria e prática pode ser observado na fala de S2, para quem a nutrição deve ter foco na saúde: "Por mais que sejam várias áreas de atuação, o nutricionista preza pela saúde do indivíduo, em todas essas áreas, a parte mais importante é a saúde". S2 refere, do mesmo modo, concordar com nutricionistas que atuam visando a estética, como na fala:"...se o nutricionista quer trabalhar nessa área...ele vai ter um benefício, vai ter um retorno financeiro, eu acredito que seja uma área boa..." 


\section{Impacto das dietas restritivas}

Dietas restritivas são aquelas que tem como objetivo a restrição calórica, de macronutrientes ou grupos alimentares ${ }^{24}$. No atual contexto da busca pela magreza, a urgência em perder peso está contribuindo para o surgimento de variadas dietas ${ }^{24}$. Considerando-se o significado mais amplo de saúde, não há dietas restritivas saudáveis, já que a restrição alimentar pode causar danos físicos, psíquicos e sociais $^{24,25,26}$. Para a maioria dos entrevistados, é indevido o uso de dietas restritivas para perda de peso; mesmo os profissionais que adotam tal medida, acreditam que seu uso deve obedecer a um limite de tempo.

Esse resultado vai ao encontro da literatura especializada, que aponta resultados semelhantes, e que sustentam que à longo prazo as dietas restritivas são desacreditadas ${ }^{24,26}$. S3 compartilha desse pensamento: “... tem pessoas que elas têm uma dificuldade mesmo em perder peso, tem uma dificuldade, às vezes, em seguir um cardápio, seguir uma orientação específica, um padrão. Então, às vezes, essa estratégia é legal para essas pessoas, mas em um curto período de tempo... agora a longo prazo, pode trazer problemas muito graves".

A entrevistada S4 menciona prejuízos a saúde de quem faz dietas restritivas, além de perda de peso ineficaz “... pela experiência que eu tenho aqui na clínica, as dietas muito restritivas, lá na frente...você vai ter um problema de descompensação de minerais, nos seus exames, você pode ter um efeito rebote e ganhar tudo de novo muito rápido". Na maioria dos indivíduos, metade do peso perdido é recuperado após um ano e quase todo o peso remanescente é recuperado posteriormente ${ }^{24}$. A perda de peso efetiva demanda tempo e deve ser gradual, sem as promessas de resultados rápidos comumente difundidas pelas dietas restritivas ${ }^{24}$.

\section{Busca pelo Corpo Perfeito}

A percepção que os indivíduos possuem do corpo altera-se de acordo com o contexto sociocultural vigente, e cada época adota uma forma corporal como modelo a ser seguido $^{27,28}$. O modelo de beleza imposto pela sociedade atual inclui um corpo magro e musculoso, com o mínimo de gordura possível ${ }^{27}$. A aversão atual à gordura e ao corpo gordo se impõe como uma repulsa estética e nada tem a ver com preocupações relacionadas à saúde 27,28 .

$\mathrm{Na}$ atual pesquisa, muitos entrevistados expressaram em suas falas ter consciência dessa insistente busca pelo corpo perfeito e sem gordura. S5, por exemplo, percebe 
essa busca em suas clientes “...em busca da perfeição, em busca do bumbum na nuca, da cintura maravilhosa, é tudo pela estética, isso a gente vê muito mesmo dentro do consultório".

De acordo com um estudo realizado em Natal- RN com mulheres encarceradas em regime fechado, a maioria deseja ter corpos maiores ao invés de silhuetas mais magras $^{29}$. O contexto social em que essas mulheres estão inseridas estabelece padrões e referências próprios sobre o corpo normal, adequado e desejável: no ambiente hostil e vulnerável de cárcere um corpo maior impõe mais respeito na medida em que tende a garantir maior segurança física ${ }^{29}$.

O ideal de corpo a ser atingido é reforçado pela mídia, que associa imagens de corpos perfeitos à felicidade e sucesso ${ }^{28}$. S6 comenta a relação entre mídia e busca pelo corpo ideal, como segue: "...aí a pessoa começa a se frustrar em busca desse corpo perfeito ... hoje no Instagram você vê a todo momento, até mesmo nutricionistas, com o corpo perfeito ... isso vai entrando na cabeça da pessoa e ela vai ficando doida".

Os corpos perfeitos veiculados pela mídia são bem diferentes dos corpos reais, fazendo com que as pessoas adotem atitudes extremadas em busca do corpo ideal, causando prejuízos à saúde e experienciando um sentimento de desconforto constante, de inadequação em relação à própria imagem ${ }^{28,30}$. Estudos ${ }^{8,31}$ apontam que a insatisfação com a imagem corporal é achado frequente nos resultados das pesquisas.

\section{Dificuldades no trabalho como nutricionista}

Dificuldades na profissão de nutricionistas são frequentemente relatadas em estudos ${ }^{16,17,18,32,33,34}$. Há relatos de insatisfação com o salário, organização do trabalho, pouco reconhecimento, falta de material, condições inadequadas e desvalorização profissional ${ }^{16,17}$. Outro problema relatado é a baixa adesão dos pacientes às prescrições dietéticas, com recorrente abandono ao tratamento nutricional ${ }^{32,33}$. A formação do nutricionista, restrita à concepção de uma dimensão puramente biológica do indivíduo, tende a não valorizar estratégias de mudanças comportamental 35 .

É essencial que o nutricionista entenda que o ser humano não se alimenta apenas por necessidade fisiológica e que a alimentação possui um papel social, cultural e psicológico5. Para a mudança do comportamento alimentar ser efetiva, o nutricionista deve ter uma atuação humanizada, desenvolvendo suas habilidades de 
escuta e empatia para poder identificar um objetivo comportamental acessível ${ }^{33}$. Assim, junto com o paciente, são estabelecidas metas e modificações possíveis de serem realizadas, e trabalhadas técnicas que podem driblar possíveis barreiras que dificultam mudanças no estilo de vida ${ }^{33}$.

No presente estudo, os nutricionistas relataram diversos tipos de dificuldades no dia a dia da profissão, corroborando com os achados na literatura, descritos acima. Uma reclamação referida por mais de um entrevistado foi a falta de adesão ao tratamento nutricional, como afirma S7: “...eles começam supermotivados e aí começa a decair. E aí você tem que se virar nos 30 para poder segurar eles e dar continuidade e terminar o tratamento...".

Uma pesquisa realizada com 150 indivíduos obesos, atendidos na clínica escola de uma faculdade de Americana-SP, teve como objetivo verificar os principais motivos do abandono ao tratamento nutricional ${ }^{34}$. O estudo mostrou que a maioria desistiu do tratamento em 30 dias ou menos e, dentre os motivos, estavam falta de tempo, segurança e dificuldade de deslocamento ${ }^{34}$. A adesão do paciente ao tratamento nutricional é influenciada por fatores sociais, culturais e pessoais, como questões emocionais, motivação e apoio da família32,33.

Outra questão levantada por alguns entrevistados foi a divulgação, pela mídia, de informações relacionadas à nutrição, dieta e emagrecimento, que na maioria das vezes estão equivocadas, como evidenciado na fala de S8: “...a mídia tem lançado muitas estratégias nutricionais...as pessoas já vem direcionadas para a gente querendo que a gente aborde uma estratégia específica, sem nem saber se aquela estratégia é saudável, se ela vai gerar algum prejuízo para a saúde."

Estudos evidenciam que há diversas publicações e recomendações na mídia relacionadas à alimentação, dietas e emagrecimento, incluindo revistas nãoespecializas, redes socias e blogs pessoais ${ }^{27,36,37}$. Tais publicações são feitas, muitas vezes, por pessoas leigas no assunto e não possuem bases científicas, podendo causar prejuízos na saúde de quem segue o que é recomendado ${ }^{6,37}$. O nutricionista é o profissional considerado apto para prescrever planejamentos dietéticos, sendo que o excesso de informações pode confundir as pessoas e acabar diminuindo a credibilidade deste profissional ${ }^{37}$. 


\section{Saúde como bem-estar físico, mental e social}

As definições de saúde sofrem influências do contexto sociocultural vigente, podendo variar entre indivíduos, grupos culturais e classes sociais ${ }^{38,39}$.

No início do século XX, época do movimento sanitarista, o termo saúde era relacionado à ausência de doenças ${ }^{38}$. Em 1948, após a introdução da concepção biopsicossocial do ser humano, a Organização Mundial da Saúde (OMS) definiu saúde em seu sentido mais amplo, como bem-estar físico mental e social ${ }^{40}$. Este é o conceito utilizado, hoje, pelos profissionais de saúde ${ }^{39}$.

No presente estudo o conceito de saúde que mais apareceu foi o de bem-estar físico, mental e social, corroborando a concepção proposta pela $\mathrm{OMS}^{4^{0}}$. S9 afirma que, para ela, uma pessoa saudável é alguém que "... pratica atividade física, que tem uma alimentação saudável, uma pessoa que tem vida social....Felicidade é ser saudável".

Devido à preocupação excessiva com o corpo e a aparência, o significado de saúde vem se alterando significativamente, incorporando apenas questões de natureza estéticas $^{36}$. Se torna saudável aquela pessoa que possui a forma física considerada ideal pela sociedade, um corpo magro, malhado, sem gorduras, rugas, celulites ou qualquer imperfeição que desvie do tão almejado corpo perfeito ${ }^{36}$. Nesse contexto, a relação entre saúde e magreza é evidenciada, porém, em muitos casos, a busca pela magreza está mais relacionada à uma questão de status, poder e reconhecimento social do que a aquisição de uma melhor saúde ${ }^{23}$.

Neste estudo, está presente uma visão crítica da concepção que associa magreza com saúde, como evidenciado na fala de S10: "Para mim, uma pessoa saudável não é aquela pessoa que aparenta uma magreza porque nem sempre o magro é saudável, mas é aquela pessoa...que está buscando mesmo esse bem-estar, em todos os sentidos...independente da aparência física..."

A busca obsessiva pelo corpo magro aumenta os riscos de transtornos alimentares, além de poder causar frustração, culpa, vergonha, depressão e baixa autoestima, impactando negativamente na saúde física, mental e social dos indivíduos ${ }^{28}$. Nutricionistas que reforçam a associação saúde-estética podem causar danos a seus pacientes ${ }^{4}$. $\mathrm{O}$ entendimento de que o ser humano é biopsicossocial é essencial para que o nutricionista atue de forma a priorizar a saúde no seu sentido mais amplo, utilizando o alimento não com fins estéticos, mas como forma de promover saúde e prevenir doenças 4 . 
Os autores compreendem as limitações do tipo de metodologia utilizada, uma vez que o número de entrevistados reflete uma pequena parcela de nutricionistas de um determinado local, sendo que os resultados não possam ser generalizados para outras populações e em diferentes contextos.

\section{CONCLUSÃO}

Por meio da análise das entrevistas e da discussão com achados da literatura, foi possível identificar uma percepção negativa dos impactos causados pelo ideal moderno de corpo magro e malhado, na prática do nutricionista. Mesmo os profissionais que não concordam com a nutrição guiada pela estética acabam sofrendo influências desta concepção e alterando sua atuação profissional.

Observou-se um descontentamento dos profissionais em relação à atitude das pessoas que, influenciadas pelo ideal de beleza, buscam o nutricionista para emagrecer e alcançar os padrões impostos. A influência da mídia foi relacionada a um desafio da profissão: a exaustiva desmistificação de informações equivocadas. Alguns entrevistados mostram-se a favor do uso de dietas restritivas a curto prazo, desde que se tenha um acompanhamento nutricional.

Sabe-se, contudo, que as pessoas podem recorrer à estética que mais lhe agradar e, ainda sim, serem saudáveis. Como exposto, a estética não irá determinar a saúde de um indivíduo, mas, sim, inúmeros fatores atuando conjuntamente. A discussão e reflexão aqui proposta refere-se à atitude de sobrepor estética corporal à saúde dos pacientes.

Por fim, percebe-se a necessidade de o nutricionista fortalecer a sua real função, a de levar saúde para as pessoas através do alimento. Para isso, é essencial uma maior compreensão do ser humano como ser biopsicossocial, entendendo a noção de saúde como promotora de bem-estar nas três dimensões e que o ato de comer abarca muito mais que fisiologia. Sugere-se a inserção, nos cursos de nutrição, de mais disciplinas do campo das ciências sociais e humanas, de forma a desenvolver profissionais mais generalistas e humanistas.

\section{REFERÊNCIAS}

1. Rios MTCA, Bruin MCB, Santos PL. Ensino Superior: a Psicologia na Formação do Nutricionista. Revista Brasileira de Ciências da Saúde. 2017; 21(1):77-86.

Disponível em:

http://www.periodicos.ufpb.br/index.php/rbcs/article/view/28695/16438 
2. Luz MMA, Romero ABR, Brito AKS, Batista LPR, Nogueira LT, Santos MM, et al. A formação do profissional nutricionista na percepção do docente. Interface: Comunicação Saúde Educação. 2015; 19(54):589-601. Disponível em: https://www.scielosp.org/pdf/icse/2015.v19n54/589-601/pt

3. Conselho Federal de Nutricionistas. Código de Ética do Nutricionista. Resolução CFN n. 599, 2018. Disponível em: http://www.cfn.org.br/wpcontent/uploads/resolucoes/Res_599_2018.htm

4. Cori GC, Petty MLB, Alvarenga MS. Atitudes de nutricionistas em relação a indivíduos obesos - um estudo exploratório. Revista Ciência \& Saúde Coletiva. 2015; 20(2):565-576. Disponível em: https://www.scielosp.org/pdf/csc/2015.v20n2/565-576/pt

5. Lima RS, Neto JAF, Faria RCP. Alimentação, comida e cultura: o exercício da comensalidade. Demetra: Alimentação, Nutrição \& Saúde. 2015; 10(3): 507-522. Disponível em: http://www.epublicacoes.uerj.br/index.php/demetra/article/view/16072/13748

6. Magalhães LM, Brasil AC, Tiengo BA. A influência de blogueiras fitness no consumo alimentar da população. Revista Brasileira de Obesidade, Nutrição e Emagrecimento. 2017; 11(68): 685-692. Disponível em: http://www.rbone.com.br/index.php/rbone/article/view/629/492

7. Torres AAL. Ponto de equilíbrio entre a Ciência da Nutrição e "Fat Studies". Demetra: Alimentação, Nutrição \& Saúde. 2016; 11(1): 1201-1212. Disponível em: http://www.e-publicacoes.uerj.br/index.php/demetra/article/view/25885/19449

8. Souza AC, Alvarenga MS. Insatisfação com a imagem corporal em estudantes universitários - Uma revisão integrativa. Jornal Brasileiro de Psiquiatria. 2016; 65(3): 286-99. Disponível em:

http://www.scielo.br/scielo.php?script=sci arttext\&pid=S004720852016000300286\&lng=pt\&tlng=pt

9. Cruz RMO, Machado BRC, Mota JN, Albuquerque SO, D`Avila LSP, Oliveira CSB. Comportamento alimentar e o posicionamento ético do profissional nutricionista. Revista Eletrônica Acervo Saúde. 2018; 12: 1277-1281. Disponível em: https://www.acervosaude.com.br/doc/REAS224.pdf

10. Guest G; Bunce A; Johnson L. How Many Interviews Are Enough? An Experiment with Data Saturation and Variability. Field methods. 2006; 18: 59-82.

11. Minayo MCS. O Desafio do Conhecimento-Pesquisa Qualitativa em Saúde. São Paulo: Hucitec. $8^{\text {a }}$ ed. 2004.

12. Fontanella BJB; Saidel MG. Amostragem em pesquisas qualitativas: proposta de procedimentos para constatar saturação teórica. Cadernos de Saúde Pública. 2011; 27(2).

13. Fontanella BJB; Campos CJG; Turato ER. Coleta de dados na pesquisa clínicoqualitativa: uso de entrevistas não-dirigidas de questões abertas por profissionais da saúde. Revista Latino-Americana de Enfermagem. 2006; 14(5): 33-40.

14. Bardin L. Análise de Conteúdo. Lisboa, Portugal; 70ª ed. 2009.

15. Souza JCN; Fagundes A; Silva DG; Barbosa KBF. Formação, satisfação e perspectivas profissionais de egressos nutricionistas de uma universidade federal do nordeste brasileiro. Demetra: Alimentação, Nutrição e Saúde. 2018; 13(1): 5- 
Fernanda Fonseca Barbosa Mendes, Maria Vilela Pinto Nakasu | Percepção de nutricionistas sobre sua atuação profissional no contexto de supervalorização do corpo magro e escultural

20. Disponível em: https://www.e-

publicacoes.uerj.br/index.php/demetra/article/view/28602

16. Trindade NR; Santana PO; Pinho L. Qualidade de vida dos nutricionistas do norte de Minas Gerais. Revista da Associação Brasileira de Nutrição. 2016; 7(2): 17-23.

Disponível em: https://rasbran.emnuvens.com.br/rasbran/article/view/186

17. Honorio ARF; Batista SH. Percepções e demandas de nutricionistas da alimentação escolar sobre sua formação. Trabalho, Educação e Saúde. 2015; 13(2): 473-492. Disponível em: http://www.scielo.br/scielo.php?pid=S1981$77462015000200473 \&$ script $=$ sci abstract\&tlng=pt

18. Souza LKCS; Campos FM; Kraemer FB; Machado PAN; Carvalho MCVS; Prado SP. Gênero e formação profissional: considerações acerca do papel feminino na construção da carreira de nutricionista. Demetra: Alimentação, Nutrição e Saúde. 2016; 11(3): 773-788. Disponível em: https://www.e publicacoes.uerj.br/index.php/demetra/article/view/23426

19.Pereira TN; Nascimento FA; Bandoni DH. Conflito de interesses na formação e prática do nutricionista: regulamentar é preciso. Ciência \& Saúde Coletiva. 2016; 21(12): 3833-3844. Disponível em:

http://www.scielo.br/scielo.php?script=sci abstract\&pid=S141381232016001203833\&lng=pt\&nrm=iso

20. Romani PF; Strey MN. Hábitos alimentares saúde e cultura o olhar de profissionais da nutrição em uma cidade de colonização italiana. Revista Conhecimento Online. 2019; 1(1): 66-86. Disponível em: https://periodicos.feevale.br/seer/index.php/revistaconhecimentoonline/article /viewFile/1490/2271

21. Santos JCR; Rocha KM; Baroneza AM; Fernandes DR; Souza VV; Baroneza JE. Metodologias ativas e interdisciplinaridade na formação do nutricionista. Ciências Socias e Humanas. 2017. 38 (1): 117-128. Disponível em: http://www.uel.br/revistas/uel/index.php/seminasoc/article/view/28205/21729

22. Recine E; Gomes RCF; Fagundes AA; Pinheiro ARO; Teixeira BA; Souza JS; Toral N; Monteiro RA. A formação em saúde pública nos cursos de graduação de nutrição no Brasil. Revista de Nutrição de Campinas. 2012. 25(1):21-33. Disponível em: http://www.scielo.br/scielo.php?pid=S1415$52732012000100003 \&$ script $=$ sci_abstract $\&$ tlng=pt

23. Silva BL; Cantisanil JR. Interfaces entre a gordofobia e a formação acadêmica em nutrição - um debate necessário. Demetra: Alimentação, Nutrição e Saúde. 2018. 13(2): 363-380. Disponível em: https://www.epublicacoes.uerj.br/index.php/demetra/article/view/33311

24. Job AR; Oliveira ACS. Percepção dos acadêmicos de nutrição sobre a efetividade a longo prazo dos métodos de dietas restritivas para a perda e o controle de peso. Revista Brasileira de Obesidade. 2019.13(78): 291-298. Disponível em: http://www.rbone.com.br/index.php/rbone/article/view/941

25. Pereira GAL; Motal LGS; Caperuto EC; Chaud DMA. Adesão de dietas da moda por frequentadores de academias de musculação do município de São Paulo. Revista Brasileira de Nutrição Esportiva. 2019. 13(77): 131-136. Disponível em: http://www.rbne.com.br/index.php/rbne/article/view/1268

26. Nogueira LR; Mello AV; Spinelli MGN; Morimoto JM. Dietas da moda consumidas por desportistas de um clube e academias em São Paulo. Revista Brasileira de 
Fernanda Fonseca Barbosa Mendes, Maria Vilela Pinto Nakasu | Percepção de nutricionistas sobre sua atuação profissional no contexto de supervalorização do corpo magro e escultural

Nutrição Esportiva. 2016. 10(59): 554-561. Disponível em: http://www.rbne.com.br/index.php/rbne/article/view/689

27. Souza LMA; Sanches RD. O corpo no discurso midiático das dietas - efeitos do novo e da novidade. Revista Famecos (Online). 2018. 25(1). Disponível em: http://revistaseletronicas.pucrs.br/ojs/index.php/revistafamecos/article/view/2 7408

28. Silva AFS; Neves LS; Japur CC; Penaforte TR; Penaforte FRO. Construção imagético-discursiva da beleza corporal em mídias sociais - repercussões na percepção sobre o corpo e o comer dos seguidores. Demetra: Alimentação, Nutrição e Saúde. 2018. 13(2): 395-411. Disponível em: https://www.epublicacoes.uerj.br/index.php/demetra/article/view/33305

29. Andrade ALCC; Barbosa APDI; Bagni UV. Imagem corporal no cárcere percepções de mulheres privadas de liberdade. Demetra: Alimentação, Nutrição e Saúde.2018. 13(2); 381-393. Disponível em: https://www.epublicacoes.uerj.br/index.php/demetra/article/view/33309

30. Gori M; Viebig RF. Influência da mídia sobre a aparência de professoras de São Paulo. Demetra: Alimentação, Nutrição e Saúde. 2018. 13(2): 447-462.

Disponível em: https://www.epublicacoes.uerj.br/index.php/demetra/article/view/32667

31. Lira AG; Ganen AP; Lodi AS; Alvarenga MS. Uso de redes sociais, influência da mídia e insatisfação com a imagem corporal de adolescentes brasileiras. Jornal Brasileiro de Psiquiatria. 2017. 66(3) -164-71. Disponível em: http://www.scielo.br/scielo.php?script=sci arttext\&pid=S004720852017000300164

32.Torres AAL. Adesão ao tratamento dietético para o emagrecimento: da teoria à prática. Revista Brasileira de Nutrição Funcional. 2019. 43(78). Disponível em: https://www.vponline.com.br/portal/noticia/pdf/e54b8abafcd2ced233931cc42bc 5f78e.pdf

33.Demenech MC; Bernardes S. Metas alimentares versus dieta - qual oferece melhores resultados em pacientes com excesso de peso. Revista da Associação Brasileira de Nutrição. 2017. 8(1): 26-30. Disponível em: https://www.rasbran.com.br/rasbran/article/view/466

34. Soares AM; Oliveira C; Rocha TR; Cordoba GMC; Nobre JAS. Porque obesos abandonam o planejamento nutricional em uma clínica-escola de nutrição. Revista Brasileira de Obesidade. 2017. 11(66):368-375. Disponível em: http://www.rbone.com.br/index.php/rbone/article/view/551

35. Araújo KL; Pena PGL; Freitas MCS; Diez-Garcia RW. Estigma do nutricionista com obesidade no mundo do trabalho. Revista de Nutrição de Campinas. 2015. 28(6):569-579. Disponível em: http://www.scielo.br/scielo.php?pid=S1415$52732015000600569 \&$ script $=$ sci abstract\&tlng $=p t$

36. Ferreira FR. Algumas considerações acerca da medicina estética. Ciência e Saúde coletiva. 2010. 15(1):67-76. Disponível em: http://www.scielo.br/scielo.php?pid=S1413$81232010000100012 \&$ script $=$ sci abstract\&tlng $=$ pt

37. Mota JJO; Almeida LC; Neves VHS; Silva EB; Oliveira DA. Análise de conteúdos de posts sobre alimentação divulgados por influenciadoras digitais na rede social 
Instagram. Demetra: Alimentação, Nutrição e Saúde. 2019. 14: 1-18. Disponível em: https://www.e-publicacoes.uerj.br/index.php/demetra/article/view/39076

38. Araújo JS; Xavier MP. O conceito de saúde e os modelos de assistência considerações e perspectivas em mudança. Revista Saúde em Foco. 2014. 1(1): 117-149. Disponível em: http://www4.fsanet.com.br/revista/index.php/saudeemfoco/article/view/326/3 82

39. Gonçalves DVC; Brito LC; Carvalho MR; Sampaio CA. Percepção sobre o Adoecimento entre Estudantes de Cursos da Área da Saúde. Revista Brasileira de Educação Médica. 2015. 39 (1): 102 - 111. Disponível em: http://www.scielo.br/scielo.php?pid=S010055022015000100102\&script=sci abstract\&tlng=pt

40. World Health Organization (WHO). Officials Records of the World Health Organization. New York: WHO; 1948.

Submissão: 12/02/2020

Aprovação: 20/09/2020 